\title{
Single Fulcrum Laparoscopic Cholecystectomy in Situs Inversus Totalis
}

\author{
Sun Jung Kim, M.D., Jiae Park, M.D., Ph.D., Chang Moo Kang, M.D., Ph.D., Woo Jung Lee, M.D., Ph.D. \\ Department of HBP Surgery, Yonsei University College of Medicine, Pancreaticobiliary Cancer Clinic, Yonsei Cancer Center, Severance Hospital, Seoul, Korea
}

\begin{abstract}
Single fulcrum laparoscopic cholecystectomy (SFLC) is a modified version of single incision laparoscopic cholecystectomy (SILC). In this article we report on the first experience of SFLC in a patient with situs inversus totalis (SIT). A 36-year-old female patient with SIT whose gallbladder was located on the left side was admitted to hospital due to a symptomatic gallbladder stone; $2 \mathrm{~cm}$ of transumbilical skin and subcutaneous fat layer were dissected and the fascia layer was left undissected to make two openings at the upper and lower part each, dividing where trocars were placed. Compared to conventional SFLC or SILC, the right hand, which is dominant for most people, performed the main operating movements, such as cutting and clipping, while the other hand was retracting the fundus of the gallbladder to show the Calot triangle. SFLC is a facilitating operation in that it does not require a specialized trocar or instruments, and is also convenient for a patient with SIT.
\end{abstract}

Keywords: Single fulcrum laparoscopic cholecystectomy, Situs inversus totalis, Single incision laparoscopic cholecystectomy

\author{
Received April 20, 2015 \\ Revised July 1, 2015 \\ Accepted August 10, 2015 \\ Corresponding author \\ Chang Moo Kang \\ Department of HBP Surgery, Yonsei \\ University College of Medicine, \\ Pancreaticobiliary Cancer Clinic, \\ Yonsei Cancer Center, \\ Severance Hospital, 250, Seongsanno, \\ Seodaemun-gu, Seoul 03722, Korea \\ Tel: +82-2-2228-2135 \\ Fax: +82-2-313-8289 \\ E-mail: cmkang@yuhs.ac
}

This is an Open Access article distributed under the terms of the Creative Commons Attribution Non-Commercial License (http:// creativecommons.org/licenses/by-nc/4.0/) which permits unrestricted non-commercial use, distribution, and reproduction in any medium, provided the original work is properly cited.
Copyright $@ 2015$ The Journal of Minimally Invasive Surgery. All rights reserved.

\section{INTRODUCTION}

Situs inversus totalis (SIT) is a rare congenital anomaly in which major visceral organs such as heart, lung, liver, gall bladder, stomach, spleen and even great vessels and nerves are totally inverted through the sagittal plane. When it comes to surgical aspects where inverted chest or abdominal organs are involved, the operator needs to face totally different operating environment of the opposite anatomic view and hand location for the stable surgical procedure.

What if the patient with SIT goes through cholecystectomy? Today, it is no doubt that laparoscopic cholecystectomy is a gold standard in treating benign gallbladder diseases, even in well selected gallbladder cancer. Moreover, laparoscopic single site cholecystectomy has been introduced to reduce operative wound and enhance cosmetic effects in patients under the procedure of laparoscopic cholecystectomy. However, technical difficulties and limited instrumental movements resulting from crowdedness of instruments through one single incision make surgeons require specialized trocars, instruments, and skillful surgical techniques. ${ }^{2-7}$

We have previously introduced the technique, named "single fulcrum-laparoscopic cholecystectomy (SFLC)", a modified version of single incision. The advantage of SFLC is that it does not need any specialized ports or instruments. Therefore, it is easy to set up, and calls for similar cost compared to conventional laparoscopic cholecystectomy. However, due to the fact that the instruments are intersected at the level of the fulcrum point which is the umbilical incision, surgeons need to use their non-dominant hand (left-hand) for Calot 
dissection (Most surgeons are right handed dominant.) while the other hand is occupied for retracting the gallbladder to show the Calot triangle.

In this report, we present the first experience of SFLC in patient with SIT to suggest its technical feasibility and safety.

\section{CASE REPORT}

\section{Patient}

A 36-year-old female patient with situs inversus totalis was admitted to hospital due to symptomatic gallbladder stone (Fig. 1). Two years ago, she had undergone 2 major heart surgeries (Tricuspid annuoplasty, Pulmonary valve replacement) (Fig. 2) for

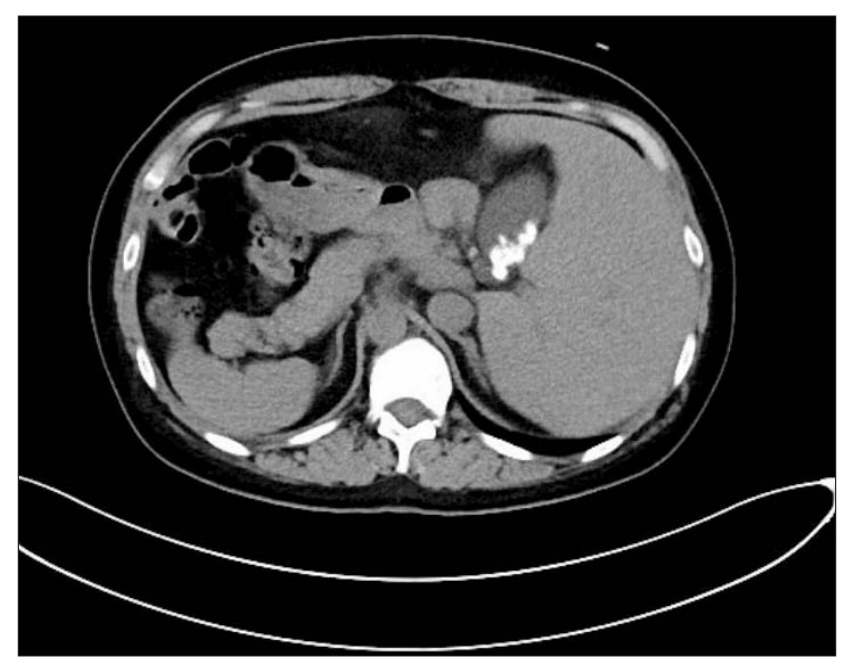

Fig. 1. Gall stones shown at the CT scan on the left side of the patient along with the liver. Pancreas and spleen are located on the opposite site from the normal anatomy. consequent congenital heart diseases and had taken oral warfarin. On history taking and physical examination, recurrent upper abdominal pain and discomfort were noted. We decided to perform SFLC for the patient.

\section{Operation}

The technique of SFLC already has been described. ${ }^{8}$ In brief, transumbilical skin was incised for $2 \mathrm{~cm}$ vertically and subcutaneous fat was also incised apart to expose the fascia layer. A small vertical incision in the upper part of the $\mathrm{ex}^{-}$ posed fascia layer was made to insert $10-\mathrm{mm}$ trocar for laparoscope. After making the $\mathrm{CO} 2$-filled pneumoperitoneum, $30^{\circ}$ angulated straight laparoscope with the vertical light cable adapted to right-angle cable connector was introduced through the $10-\mathrm{mm}$ trocar. Then miniaturized $5-\mathrm{mm}$ trocar and a $2 \mathrm{~mm}$ trocar were inserted together, sharing a single fulcrum in the lower part of the exposed fascia. As a result, there were two openings made in the fascia layer, not connected to each other, and the lower opening had two working instruments itself to provide the fulcrum point. The operation began with the surgeon standing on the right side of the patient, which was the opposite position for the normal SFLC. Due to reversed configuration, 2-mm grasper was handled by surgeon's left hand and 5-mm effectors, such as dissector and mono-polar hook, was controlled by surgeon's dominant right hand. As shown in preoperative image, internal organs were in a total inverse location (Fig. 3A). By retracting the infundibulum laterally with the 2-mm grasper, the anterior aspect of Calot triangle was exposed and dissected with the 5-mm dissector and hook coagulator. The lower part of the gallbladder was separated from the cystic plate. The gall bladder retraction was performed with percutaneous needle insertion (Fig. 3B). There were moderate degree of
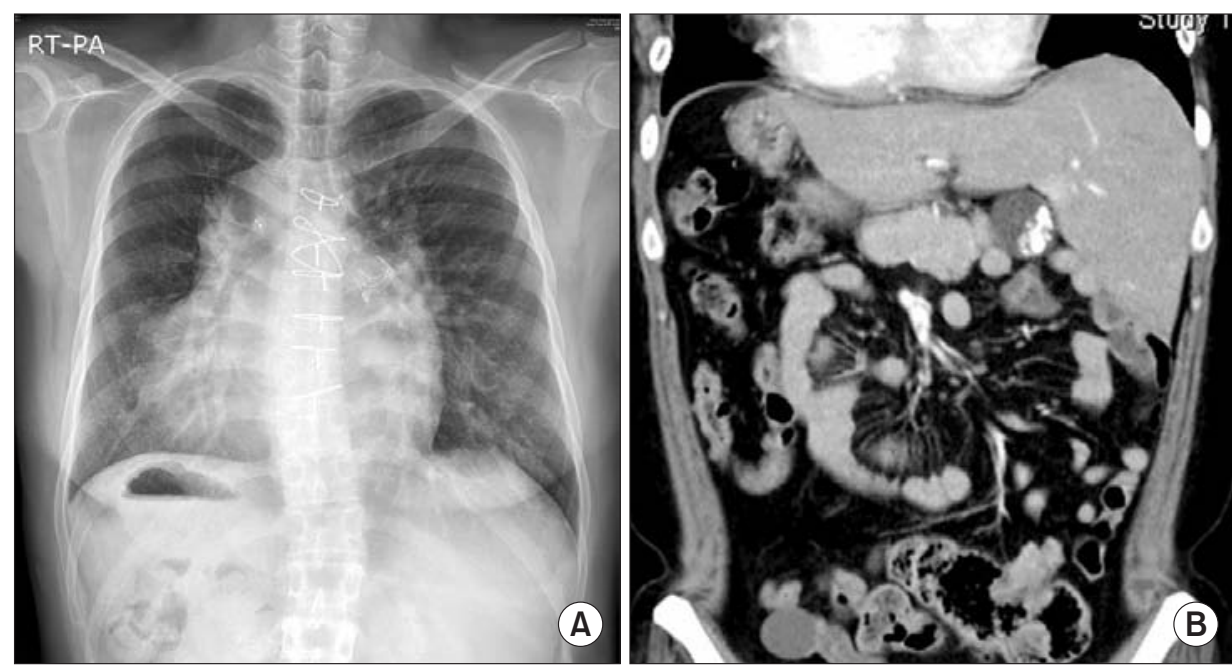

Fig. 2. (A) On chest PA, previous open heart surgery is suspected. Cardiomegaly, inverted orientation of the heart, and right sided gastric gas shadow are noted. (B) The abdominal $x$-ray shows dextrocardia. 

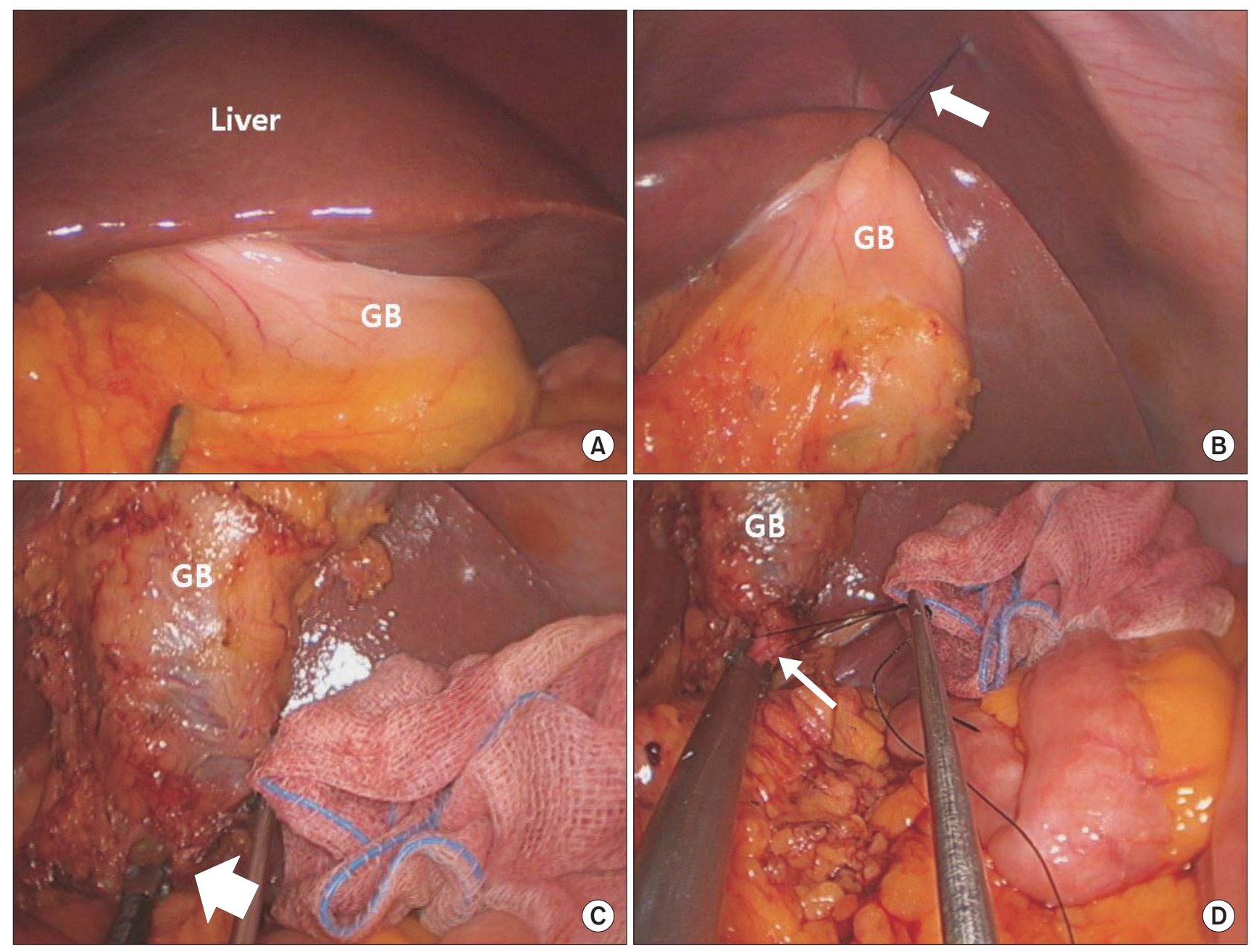

Fig. 3. (A) Gall bladder below the liver on the left side of the patient is detected. (B) The proximal fundus of gall bladder is pulled upward via nylon suture (white arrow) (C) Isolating the cystic duct (white, thick, and short arrow) free with the right angle dissector (white, thin, and short arrow) (D) Ligation and retraction of cystic duct with endo-clip and 4-0 silk each (white, thin, and long arrow).

omental adhesions around gallbladder due to inflammation of acute cholecystis ${ }^{9}$ and the adhesions were removed from the gallbladder. After skeletonizing, cystic artery was clipped and divided and cystic duct also was inflamed and dilated. After isolation of cystic duct with right angle dissector, cystic duct was ligated and then retracted with 4-0 silk (Fig. 3C, 3D). Others were the same as usual procedures of SFLC. And the gallbladder was removed from the liverbed in a bottom-to-top fasion. No bleeding, no gallbladder perforation, no bile leak was noted during the operation.

\section{Postoperative course}

The patient took oral diet on operation day. After surgery, she needed to stay for 8 days in hospital for conversion of intake of intravenous heparin to oral warfarin. There was no surgery-related complication. Pathologic examination reported chronic cholecystitis without evidence of malignancy.

\section{DISCUSSION}

Abdominal surgery in patients with SIT must be challenging, even for well-experienced surgeons because all anatomic arrangements of internal organs are a mirror image to the normal ones. Although laparoscopic cholecystectomy is thought to be simple and common, it could be quite a bit of a demand in patients with SIT.

There are a few reports about single site laparoscopic cholecystectomy in SIT (Table 1). Different surgical techniques were applied, but they all suggested that every patients with gallbladder diseases can be managed successfully and take great advantages of minimally invasive surgery. SFLC has 
Table 1. Literatures reporting single site laparoscopic cholecystectomy in situs inversus totalis

\begin{tabular}{|c|c|c|c|c|c|c|c|}
\hline Author, Year & $\begin{array}{l}\text { Agel } \\
\text { Gender }\end{array}$ & $\begin{array}{l}\text { Gallbladder } \\
\text { Disease }\end{array}$ & Surgical System & $\begin{array}{l}\text { Specialized } \\
\text { instrument }\end{array}$ & $\begin{array}{l}\text { Operation } \\
\text { Time (min) }\end{array}$ & Complication & $\begin{array}{l}\text { Hospital } \\
\text { Stay }\end{array}$ \\
\hline $\mathrm{Han}^{4}, 2011$ & $45 / M$ & GB stone & Hand-made Globe port & Roticulating instruments & 77 & No & 2 \\
\hline Uludag', 2011 & 49/M & GB stone & SILS port (Covidien) & Roticulating instruments & 75 & No & 1 \\
\hline Ozsoy ${ }^{6}, 2011$ & $64 / F$ & GB stone & SILS port (Covidien) & Roticulating instruments & NA & No & 1 \\
\hline $\begin{array}{l}\text { De Campos Martin }{ }^{3} \text {, } \\
2012\end{array}$ & $59 / F$ & GB stone & $\begin{array}{l}\text { SITRACC port } \\
\text { (Eldo, Porto Alegre, Brazill) }\end{array}$ & Flexible instrument & NA & No & 2 \\
\hline Bozkurt², 2012 & 49/M & GB stone & Single port (Ethicon) & Roticulating instruments & 90 & No & 1 \\
\hline Khiangte ${ }^{5}, 2013$ & $65 / F$ & GB stone & $\begin{array}{l}\text { Hand-made Glove Port } \\
\text { (E.K. glove port) }\end{array}$ & Roticulating instruments & 70 & No & 2 \\
\hline Current & $36 / F$ & GB stone & Single fulcrum & None & 80 & No & $8^{*}$ \\
\hline
\end{tabular}

*The patient needed to be managed for conversion from intravenous heparin to oral warfarin.

been introduced as an alternative approach to simplify the procedures of docking the trocars. One of the disadvantages of SFLC is that the operators need to use their non-dominant hand (left hand) for Calot dissection. The operator's right hand takes the grasper to pull the infundibulum of gall bladder laterally and the left hand does tissue dissection, clipping, and cutting of the cystic artery/duct. Otherwise it'll be unstable to control the grasper and dissector. Fortunately this dissection-movement is relatively simple and is believed to be compensated even by non-dominant surgeon's left hand.

The current case is suggesting that SFLC is feasible and safe even in SIT patient with gallbladder disease. Other laparoscopic techniques for single site cholecystectomy are reported as safe and effective approach. ${ }^{2-7}$ However, these all require advanced surgical skills and experiences to perform a safe laparoscopic cholecystectomy. Recently, single site robotic surgical system has been introduced to make laparoscopic surgery easier, safer, and more effective. We have reported the first experiences of robotic single site cholecystectomy in Asia. ${ }^{10}$ SIT-induced left and right orientation-problem will be resolved in robotic surgical system. Although robotic surgical system still has several issues to be discussed, it is thought that robotic single site cholecystectomy can be a good alternative for laparoscopic single site cholecystectomy. If only the patient agrees to get the robotic surgery, it would be safer for patients and more convenient for surgeons. In near future, it may expand the chance of minimally invasive cosmetic surgery in patients requiring laparoscopic cholecystectomy.

\section{REFERENCES}

1) Dalal J, et al. Situs inversus totalis. Journal of Punjab Academy of Forensic Medicine \& Toxicology 2004;4:35-36.

2) Bozkurt S, et al. Single Incision Laparoscopic Cholecystectomy in situs Inversus Totalis. J Surg Tech Case Rep 2012;4:129-131.

3) de Campos Martins MV, et al. Single-port cholecystectomy in a patient with situs inversus totalis presenting with cholelithiasis: a case report. J Med Case Rep 2012;6:96.

4) Han HJ, et al. Single-incision multiport laparoscopic cholecystectomy for a patient with situs inversus totalis: report of a case. Surg Today 2011;41:877-880.

5) Khiangte E, et al. Single-port laparoscopic cholecystectomy in situs inversus totalis using the E.K. glove port. J Minim Access Surg 2013;9:180-182.

6) Ozsoy M, Haskaraca MF, Terzioglu A. Single incision laparoscopic cholecystectomy (SILS) for a patient with situs inversus totalis. BMJ Case Rep 2011;2011.

7) Uludag M, Yetkin G, Kartal A. Single-incision laparoscopic cholecystectomy in situs inversus totalis. JSLS 2011;15:239-243.

8) Choi SH, et al. Single-fulcrum laparoscopic cholecystectomy: a single-incision and multi-port technique. ANZ J Surg 2012;82: 529-534.

9) Yamashita Y, et al. TG13 surgical management of acute cholecystitis. J Hepatobiliary Pancreat Sci 2013;20:89-96.

10) Lee $\mathrm{SH}$, et al. The first experiences of robotic single-site cholecystectomy in Asia: a potential way to expand minimally-invasive single-site surgery? Yonsei Med J 2015;56:189-195. 